\title{
Multiple pathways are responsible for Anti-inflammatory and Cardiovascular activities of Hordeum vulgare L.
}

\author{
Saima Gul', Sagheer Ahmed ${ }^{1,2}$, Nurolaini Kifli ${ }^{1}$, Qazi Tahir Uddin ${ }^{3}$, Nafisa Batool Tahir ${ }^{4}$, Abrar Hussain $^{5}$,
} Hawa ZE Jaafar ${ }^{6^{*}}$, Marius Moga ${ }^{7^{*}}$ and Muhammad Zia-Ul-Haq ${ }^{8^{*}}$

\begin{abstract}
Background: Hordeum vulgare L. (HV or barley) is used by traditional healers to treat various inflammatory and cardiovascular diseases, without the knowledge of pharmacologic rationale behind its actions. This study was designed to explore the potential scientific mechanism(s) that could explain the use of Hordeum vulgare in traditional medicine as a treatment for various inflammatory and cardiovascular diseases.

Methods: A crude extract and its three fractions were prepared from HV and screened for the inhibition of platelet aggregation and various metabolites of cyclooxygenase (COX), lipoxygenase (LOX) pathways of arachidonic acid (AA) metabolism as well as for its effects on certain antioxidant enzymes. Platelet aggregation was monitored using turbidometric principle, AA metabolism through radioimmunoassay and antioxidant enzymes by commercial kits using spectrophotometer.

Results: Results show that HV exhibited activities against all human platelet agonists used except adenine diphosphate, and inhibited both COX and LOX pathways of AA metabolism. It also elevated the activities of superoxide dismutase (SOD) and glutathione peroxidase (GPX). However, these activities were distributed in various fractions of HV. Aqueous fraction was most potent in elevating SOD activity; chloroform fraction had concentrated compounds responsible for COX inhibition while n-hexane seems to possess compounds responsible for LOX inhibition as well as the only fraction enhancing the activity of GPX.
\end{abstract}

Conclusions: These results suggest the likely mechanisms responsible for observed anti-inflammatory and cardiovascular effects of HV in traditional medicine.

Keywords: Inflammation, Hordeum vulgare, Platelets, Cyclooxygenase, Lipoxygenase, Superoxide dismutase, Glutathione peroxidase

\section{Background}

World literature, especially, Greek, Roman and Egyptian literatures point to the dietary and medicinal properties of Hordeum vulgare L. (HV) [1]. HV, a member of the grass family, Poaceae, is an annual crop used throughout ancient civilizations as an important food source. The genus Hordeum consists of 32 species and 45 taxa. HV

\footnotetext{
*Correspondence: hawazej@gmail.com; moga.og@gmail.com; ahirzia@gmail.com ${ }^{6}$ Department of Crop Science, Faculty of Agriculture, University Putra Malaysia, 43400 Selangor, Malaysia

${ }^{7}$ Department of Medical and Surgical Specialities, Transilvania University of Brasov, Brasov, Romania

${ }^{8}$ The Patent Office, Karachi, Pakistan

Full list of author information is available at the end of the article
}

belong to a single biological species, which is an annual and is diploid. All varieties of HV have hollow stems in the forms of cane, produced from fibrous roots. There is a spike-shaped arrangement of seed at the end of each stem.

Until the $19^{\text {th }}$ century, barley was the major part of diet of millions of people. Even now, it is eaten as such or in processed form, in various quantities at various ontogenic stages by people of all income and age groups globally as functional food. Various clinical and preclinical studies have confirmed the positive and beneficial effects of barley on human health. Consumption of barley which contains many medicinally active phytocompounds is usually associated with improvement in

\section{Biomed Central}

(c) 2014 Gul et al.; licensee BioMed Central Ltd. This is an Open Access article distributed under the terms of the Creative Commons Attribution License (http://creativecommons.org/licenses/by/4.0), which permits unrestricted use, distribution, and reproduction in any medium, provided the original work is properly credited. The Creative Commons Public Domain Dedication waiver (http://creativecommons.org/publicdomain/zero/1.0/) applies to the data made available in this article, unless otherwise stated. 
health. Use of barley can protect against diabetes, obesity, atherosclerosis, cancer, stroke and insulin resistance [2].

A number of pharmacological activities of $\mathrm{HV}$ have been reported in the literature. Hot water extracts of $\mathrm{HV}$ protect from damage due to oxidation of various proteins [3]. Anti-apoptotic activity of the HV has been reported and is attributed to the presence of 3,4 dehydroxybenzaldehyde, which protects from DNA damage [4]. Lipopolysaccharideinduced inflammation is also inhibited by methanolic extract of the aerial parts of $\mathrm{HV}$, both in vitro and in vivo [5]. Barley or $\mathrm{HV}$ is also used to treat a number of diseases in traditional Ayurvedic system of medicine in India, especially in the treatment of urinary stones [6]. The growth of the urinary stones [7] as well as mild hyperuricemia [8] was found to be inhibited by using the seed extracts of HV.

The main constituents of HV include important antioxidants such as vitamin E, phytic acid, selenium, tocotrienols, and various phenolic acids. After the consumption of $\mathrm{HV}$, these antioxidants are released at differential rate throughout the gastrointestinal tract over a long period of time [9]. Health benefits of HV consumption are numerous [10] and are mainly attributed to various mineral, dietary fibres, unsaturated fatty acids and sphingolipids, in addition to the antioxidants and vitamins [11]. Apart from that a number of other antioxidant compounds have been isolated from HV [12].

$\mathrm{HV}$ is used by traditional healers to treat various inflammatory and cardiovascular diseases, without the knowledge of pharmacologic rationale behind its actions [6]. Despite the very important roles of platelets activation in the development of acute thrombosis and cardiovascular diseases (CVD), no data are available concerning the effect of barley on platelet activation thrombus formation. Since a number of plants have been reported to display inhibition of arachidonic acid (AA) metabolism and platelet aggregation [13-18], we therefore, screened various fraction of $\mathrm{HV}$ against cyclooxygenase (COX) and lipoxygenase (LOX) pathways of AA metabolism. Since both of these enzymatic pathways are implicated in oxidative stress, we further evaluated the actions of $\mathrm{HV}$ on superoxide dismutase (SOD) and glutathione peroxidase (GPx). These activities have not been previously reported for HV.

\section{Experimental section}

The chemicals used in the study were purchased from $\mathrm{BDH}$ (acetic acid and citric acid), Merck (sodium phosphate-mono and dibasic), Amersham Biosciences $\left({ }^{14} \mathrm{C}\right.$ arachidonic acid) and Sigma (the remaining), all from USA and were of analytical grade.

\section{Extraction of plant material}

Rotary evaporator was used to make crude extract of the 2000 gof barley seeds which was authenticated by a botanist and a specimen kept at the department of Pharmacy, Kohat University of Science \& Technology, Kohat, Pakistan. Barley seeds were crushed to powder before soaking it in the solvent. Five liter of aquous methanol was used to soak $1500 \mathrm{~g}$ powdered bark at $4^{\circ} \mathrm{C}$ and left for $24 \mathrm{~h}$. This mixture was filtered and then evaporated to obtain the crude extract by a rotary evaporator [19]. The resulting extract was a solid mass of dark brown color.

\section{Fractionation of the crude extract}

Fractionation of the crude extract was done by slight modification of the method described previously [20]. Crude extract (900 g) was dissolved in distilled water before intoroducing into a separating funnel. After addition of $50 \mathrm{ml}$ of $\mathrm{n}$-hexane, the whole mixture was vigorously mixed and allowed to stand at the room temperature for $30 \mathrm{~min}$. This resulted in separation of two layes. After acquiring the upper layer of n-hexane, this frcationation process was repeated twice and the resulting three nhexane fractions were combined and evaporated in the rotary evaporator to obtain n-hexane fraction. Next, $50 \mathrm{ml}$ chloroform was added to the remaining layer and again the whole fractionation process was repeated as with nhexane fraction, thus obtaining chloroform fraction. After that, the remaining layer was concentrated in the rotary evaporated to get aquous fraction.

\section{Arachidonic acid metabolism by human platelets}

Formation of AA metabolites by human platelets and its inhibition by various fractions of barley was measurd by slight modification of a method described previously [21]. Concentarted plasma $(50 \mathrm{ml})$ was obtained from the diagnostic laboratories of the Aga Khan University, Karachi. Platelet rich plasma (PRP) was obtained by subjecting concentrated platelets to centrifugation for $20 \mathrm{~min}$ at $1200 \mathrm{~g}$. This PRP was treated with phosphate buffer twice before resuspending them in the same buffer without EDTA.

The suspension was centrifuged for $20 \mathrm{~min}$ at $1200 \mathrm{~g}$ after homogenizing the PRP suspension for 15 seconds at $4^{\circ} \mathrm{C}$ using a polytron homogenizer. A $300 \mu \mathrm{l}$ supernatant was incubated with $10 \mu \mathrm{g}$ unlabelled AA and 0.1 $\mu \mathrm{Ci}\left[1-{ }^{14} \mathrm{C}\right] \mathrm{AA}$ in the presence and absence of various $\mathrm{HV}$ fractions. The reaction was allowed to proceed at $37^{\circ} \mathrm{C}$ for $15 \mathrm{~min}$. Citric acid and ethyle acetate was used to stop the reaction. The organic layer was separated under recommended standard conditions and then dried. The residues were dissolved and applied on thin layer chromatography plates. Standards for AA, thromboxane (TX) $\mathrm{B}_{2}$ (a stable degradation product of $\mathrm{TXA}_{2}$ ), lipoxygenase product-1 (LP1) and 12-hidroxy eicosatetraenoic acid (12-HETE) were plotted separately [22]. The plates were developed using different solvent systems for different products. Quantification with a Berthold TLC 
linear analyzer and chromatography data system was done after locating the radioactive zones.

\section{Preparation of platelets}

Nine ml blood was obtained from healthy human volunteers who were not on any medication for at least last 10 days. One $\mathrm{ml}$ of sodium citrate $(3.8 \%, \mathrm{w} / \mathrm{v})$ was added to the blood and mixed gently. This sample was centifuged at lower speed (at $260 \mathrm{~g}$ ) for $15 \mathrm{~min}$ to get platelet rich plasma (PRP). To get the platelet poor plasma (PPP), the remaining blood was centrifuged at higher speed (at $1200 \mathrm{~g}$ ) for $10 \mathrm{~min}$. The centrifugation was done at $20^{\circ} \mathrm{C}$ while the actual aggregation studies were performed at $37^{\circ} \mathrm{C}$. Platelet count of PRP was between 2.5 and $3.0 \times$ $10^{8} \mathrm{ml}^{-1}$ of plasma [23] as determined by phase contrast microscopy.

\section{Measurement of platelet aggregation}

Platelet aggregation was monitored in $450 \mu \mathrm{l}$ of PRP $[24,25]$. The final volume of PRP was made upto $500 \mu \mathrm{l}$ by the addition of test sample and aggregation agonist. Platelet were challenged with four aggregating agonits; platelet activating factor (PAF) $(0.8 \mu \mathrm{M})$, AA $(1.7 \mathrm{mM})$, Adenine diphosphate (ADP) $(2.2 \mu \mathrm{M})$, and collagen $(5 \mu \mathrm{g} / \mathrm{ml})$. Platelets were incubated with test fraction for 2 min before the addition of aggregating agonist. After challenging platelets with agonist, results were recorded for $5 \mathrm{~min}$ as measured by a change in the transmission of light as a function of time. Dose response curves were calculated for various fractions against different agonists and used to calculate the $1 C_{50}$ values.

\section{Glutathione peroxidase activity determination}

GPx activity was measured as described previously [26]. The test fraction is added to assay solution followed by the addition of the substrate (t-butyl-hydroperoxide) which is the last component of assay added before the chemical reaction starts. This reaction works by bringing together the reduced form of nicotinamide adenine dinucleotide phosphate (NADPH) and reduced glutathione. Addition of the substrate starts its reduction and a change in the absorbance is measured at $340 \mathrm{~nm}$. GPx activity is finally determined using glutathione as cosubstrate.

\section{Superoxide dismutase activity determination}

SOD activity was measured as described previously [27]. As done in GPx assay, the test fraction is added to assay solution followed by the addition of the substrate which is the last component of assay added before the chemical reaction starts. In this assay the substrate, 2-(4-iodophenyl)3-(4-nitrophenol)-5-phenyltetrazolium chloride (INT)) is converted to a formazane dye. Superoxide radicals are produced by xanthine and xanthine oxidase. SOD activity is directly related to the extent of inhibition of this reaction and is measured by detecting a change in absorbance at $505 \mathrm{~nm}$. Under such conditions, 50\% inhibition rate is equivalent to one unit of SOD activity.

\section{Statistical analysis}

The doses of the extract and fractions showing 50\% effect $\left(\mathrm{IC}_{50}\right.$ or $\left.\mathrm{EC}_{50}\right)$ were calculated. Means between the groups were compared using student's t-test. The difference between the means was considered significant when $\mathrm{p}<0.05$.

\section{Results}

Crude extract from HV was unable to inhibit ADP-induced platelet aggregation; however, collagen and PAF-induced aggregations were blocked partially while the most potent antiplatelet effect was observed against AA-inducedplatelet aggregation. The dose of the extract showing $50 \%$ inhibitory effect against platelet aggregation (mean $\mathrm{IC}_{50}$ value in $\mu \mathrm{g}$ ) against various agonists were $18.33 \pm 3.51$ for AA, $187.71 \pm 19.57$ for PAF, $211.23 \pm 27.92$ for collagen and $15.88 \pm 2.14$ for aspirin (positive standard control) (Table 1 and Figure 1). Crude extract of HV was also more effective against COX-mediated pathway of AA metabolism compared to LOX-mediated pathway. $\mathrm{IC}_{50}$ (mean \pm $\mathrm{SD}$ in $\mu \mathrm{g}$ ) values were $24.34 \pm 5.33$ for $\mathrm{TXB}_{2}, 78.45 \pm 12.29$ for LP1 and $89.44 \pm 16.22$ for HETE. Crude extract potently elevated SOD activity $\left(\mathrm{EC}_{50}\right.$ in $\left.\mu \mathrm{g}, 32.88 \pm 3.19\right)$ but was ineffective in increasing GPX activity up to $1 \mathrm{mg}$ dose (Table 2).

Aqueous fraction of $\mathrm{HV}$ was unable to inhibit PAF and ADP-induced platelet aggregation, however, AA and collagen -induced aggregations were blocked partially. The dose of the fraction showing 50\% inhibitory effect against platelet aggregation $\left(\mathrm{IC}_{50}\right.$ value in $\mu \mathrm{g}$ ) against various agonists were $58.73 \pm 12.82$ for $\mathrm{AA}, 121.55 \pm$ 20.32 for PAF (Table 1 and Figure 1). Aqueous fraction of $\mathrm{HV}$ was ineffective against LOX-mediated pathway of AA metabolism while partially blocking COXmediated pathway. $\mathrm{IC}_{50}$ (mean $\pm \mathrm{SD}$ in $\mu \mathrm{g}$ ) values were $74.67 \pm 12.52$ for $\mathrm{TXB}_{2}$, while no significant effect was observed on LP-1 and 12-HETE up to a dose of $1 \mathrm{mg}$. Aqueous fraction just like the crude extract potently elevated SOD activity $\left(\mathrm{EC}_{50}\right.$ in $\left.\mu \mathrm{g}, 28.21 \pm 4.73\right)$ but was ineffective in increasing GPX activity up to $1 \mathrm{mg}$ dose (Table 2).

Chloroform fraction of HV, just like the crude extract, was unable to inhibit ADP-induced platelet aggregation; however, collagen and PAF-induced aggregations were blocked partially while the most potent antiplatelet effect was observed against AA-induced-platelet aggregation. The dose of the fraction showing 50\% inhibitory effect against platelet aggregation $\left(\mathrm{IC}_{50}\right.$ value in $\mu \mathrm{g}$ ) against various agonists were $21.63 \pm 4.10$ for $\mathrm{AA}, 98.56 \pm 16.68$ 
Table 1 IC $_{50}$ (mean (SD)) of the crude extract of HV and its fractions against various platelet agonists, AA metabolites and antioxidant enzymes

\begin{tabular}{llllll}
\hline $\mathbf{N o}$ & Experiment & Crude $(\boldsymbol{\mu g})$ & Aqueous $(\boldsymbol{\mu g})$ & Chloroform $(\boldsymbol{\mu g})$ & $\mathbf{n}$-Hexane $(\boldsymbol{\mu g})$ \\
\hline $\mathbf{1}$ & PAF & $187.71(19.57)$ & $1 \mathrm{mg}$ & $98.56(16.68)$ & $97.82(15.63)$ \\
$\mathbf{2}$ & $\mathrm{AA}$ & $18.33(3.51)$ & $58.73(12.82)$ & $21.63(4.10)$ & $86.74(12.54)$ \\
$\mathbf{3}$ & Collagen & $211.23(27.92)$ & $121.55(20.32)$ & $126.73(22.36)$ & $1 \mathrm{mg}$ \\
$\mathbf{4}$ & ADP & $1 \mathrm{mg}$ & $1 \mathrm{mg}$ & $1 \mathrm{mg}$ & $1 \mathrm{mg}$ \\
$\mathbf{5}$ & $\mathrm{LP}-1$ & $78.45(12.29)$ & $1 \mathrm{mg}$ & $66.52(10.51)$ & $37.61(4.71)$ \\
$\mathbf{6}$ & $12-\mathrm{HETE}$ & $89.44(16.22)$ & $1 \mathrm{mg}$ & $118.44(19.75)$ & $60.52(4.60)$ \\
$\mathbf{7}$ & $\mathrm{TXB} 2$ & $24.34(5.33)$ & $74.67(12.52)$ & $28.63(6.76)$ & $40.34(7.46)$ \\
$\mathbf{8}$ & $\mathrm{SOD}\left(\mathrm{EC}_{50}\right)$ & $32.88(3.19)$ & $28.21(4.73)$ & $28.83(5.48)$ & $35.29(5.33)$ \\
$\mathbf{9}$ & $\mathrm{GPx}\left(\mathrm{EC}_{50}\right)$ & $1 \mathrm{mg}$ & $1 \mathrm{mg}$ & $1 \mathrm{mg}$ & $23.17(3.29)$ \\
\hline
\end{tabular}
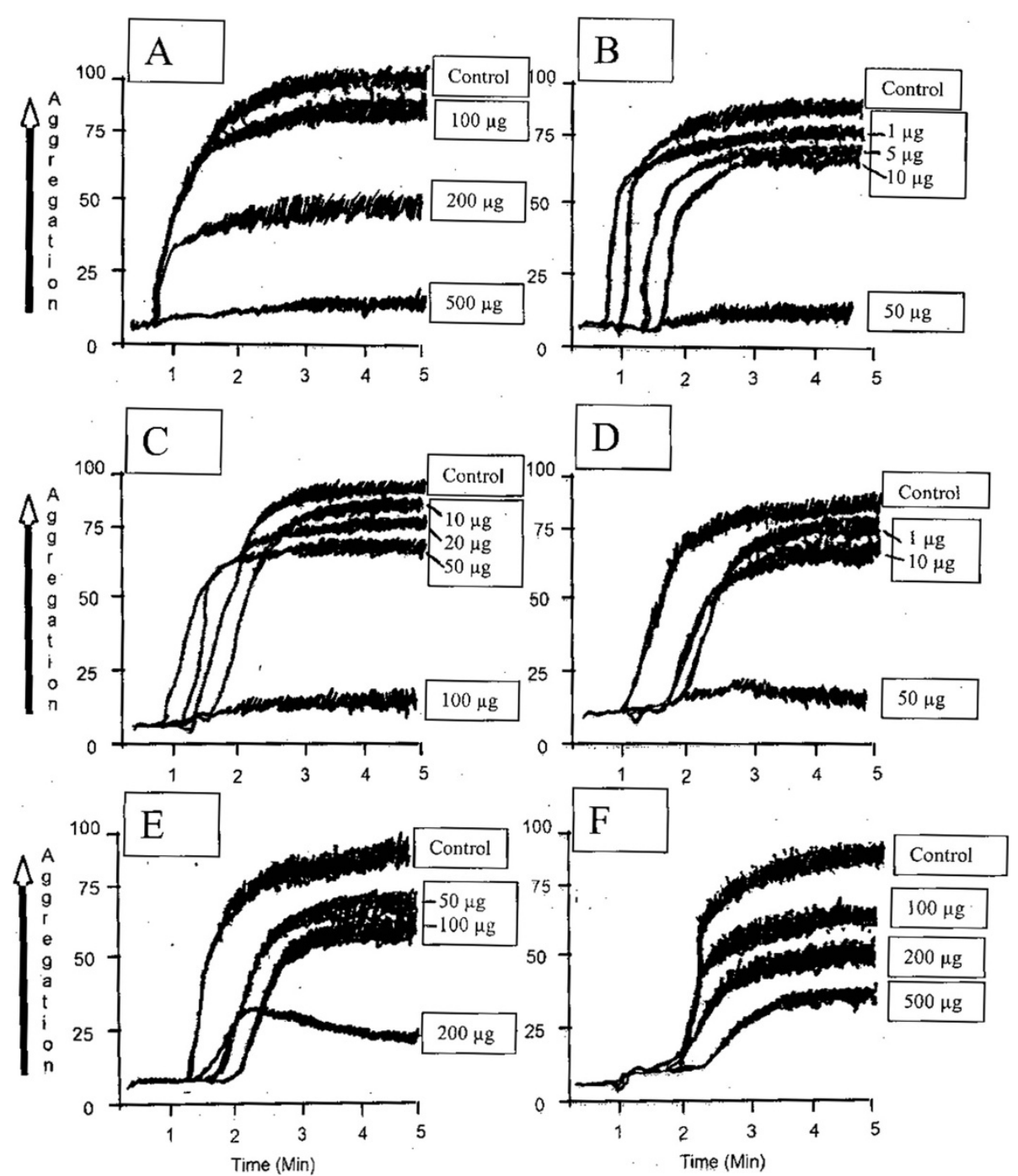

Figure 1 Representative scans of the effect of crude extract of $\mathrm{HV}$ and its fractions on platelet aggregation induced by various agonists, i.e. crude on PAF (A), crude on AA (B), aqueous on AA (C), chlororform on AA (D), n-hexane on PAF (E), aqueous on collagen (F). 
Table 2 Activities of SOD and GPx under normal and stressed conditions and the effects of the crude fraction of $\mathrm{HV}$ and its fractions, $n=6, * p<0.05$ compared to normal

\begin{tabular}{lllll}
\hline & $\begin{array}{l}\text { Dose } \\
(\boldsymbol{\mu g})\end{array}$ & $\begin{array}{l}\text { SOD } \\
\text { activity }\end{array}$ & $\begin{array}{l}\text { Dose } \\
(\boldsymbol{\mu g})\end{array}$ & $\begin{array}{l}\text { GPx } \\
\text { activity }\end{array}$ \\
\hline Normal & - & $171 \pm 9$ & - & $5872 \pm 642$ \\
$\begin{array}{l}\text { Vitamin C } \\
\text { (Standard) }\end{array}$ & 10 & $215 \pm 20^{*}$ & 10 & $8751 \pm 761^{*}$ \\
$\mathbf{H}_{\mathbf{2}} \mathbf{O}_{\mathbf{2}}$ (Stress) & $0.3 \mu \mathrm{M}$ & $148 \pm 13^{*}$ & $0.3 \mu \mathrm{M}$ & $4192 \pm 523^{*}$ \\
Crude & 20 & $184 \pm 21$ & 100 & $6145 \pm 765$ \\
& 50 & $198 \pm 19$ & 500 & $6171 \pm 625$ \\
& 100 & $212 \pm 24^{*}$ & 1000 & $6211 \pm 566$ \\
Aqueous & 10 & $181 \pm 18$ & 100 & $6257 \pm 621$ \\
& 30 & $189 \pm 20$ & 500 & $6304 \pm 724$ \\
Chloroform & 50 & $198 \pm 17^{*}$ & 1000 & $6326 \pm 844$ \\
& 10 & $179 \pm 16$ & 100 & $6352 \pm 628$ \\
& 30 & $194 \pm 20$ & 500 & $6386 \pm 863$ \\
& 50 & $207 \pm 21^{*}$ & 1000 & $6456 \pm 767$ \\
n-hexane & 20 & $184 \pm 21$ & 10 & $6002 \pm 590$ \\
& 50 & $197 \pm 23$ & 20 & $7109 \pm 653^{*}$ \\
& 100 & $213 \pm 20^{*}$ & 50 & $8663 \pm 759^{*}$ \\
\hline
\end{tabular}

for PAF, $126.73 \pm 22.36$ for collagen (Table 1 and Figure 1). Chloroform fraction of $\mathrm{HV}$ was also more effective against COX-mediated pathway of AA metabolism compared to LOX-mediated pathway. $\mathrm{IC}_{50}$ (mean $\pm \mathrm{SD}$ in $\mu \mathrm{g}$ ) values were $28.63 \pm 6.76$ for $\mathrm{TXB}_{2}, 66.52 \pm 10.51$ for LP1 and $118.44 \pm 19.75$ for HETE. Chloroform fraction just like the crude extract and aqueous fraction potently elevated SOD activity $\left(\mathrm{EC}_{50}\right.$ in $\left.\mu \mathrm{g}, 28.83 \pm 5.48\right)$ but was ineffective in increasing GPX activity up to $1 \mathrm{mg}$ dose (Table 2).

$\mathrm{n}$-hexane fraction of $\mathrm{HV}$ was unable to inhibit collagen and ADP-induced platelet aggregation, however, AA and PAF-induced aggregations were blocked partially. The dose of the fraction showing $50 \%$ inhibitory effect against platelet aggregation $\left(\mathrm{IC}_{50}\right.$ value in $\left.\mu \mathrm{g}\right)$ against various agonists were $86.74 \pm 12.54$ for AA, $97.82 \pm$ 15.63 for PAF (Table 1 and Figure 1). LOX pathway of AA metabolism was blocked potently while COX metabolite was partially inhibited. $\mathrm{IC}_{50}$ (mean $\pm \mathrm{SD}$ in $\mu \mathrm{g}$ ) values were $40.34 \pm 7.46$ for $\mathrm{TXB}_{2}, 37.61 \pm 4.71$ for LP1 and $60.52 \pm 4.60$ ) for HETE (Figure 2). n-hexane potently elevated the activities of both SOD and GPx with $\mathrm{EC}_{50}(\mu \mathrm{g})$ of $35.29 \pm 5.33$ and $23.17 \pm 3.29$ respectively (Table 2).
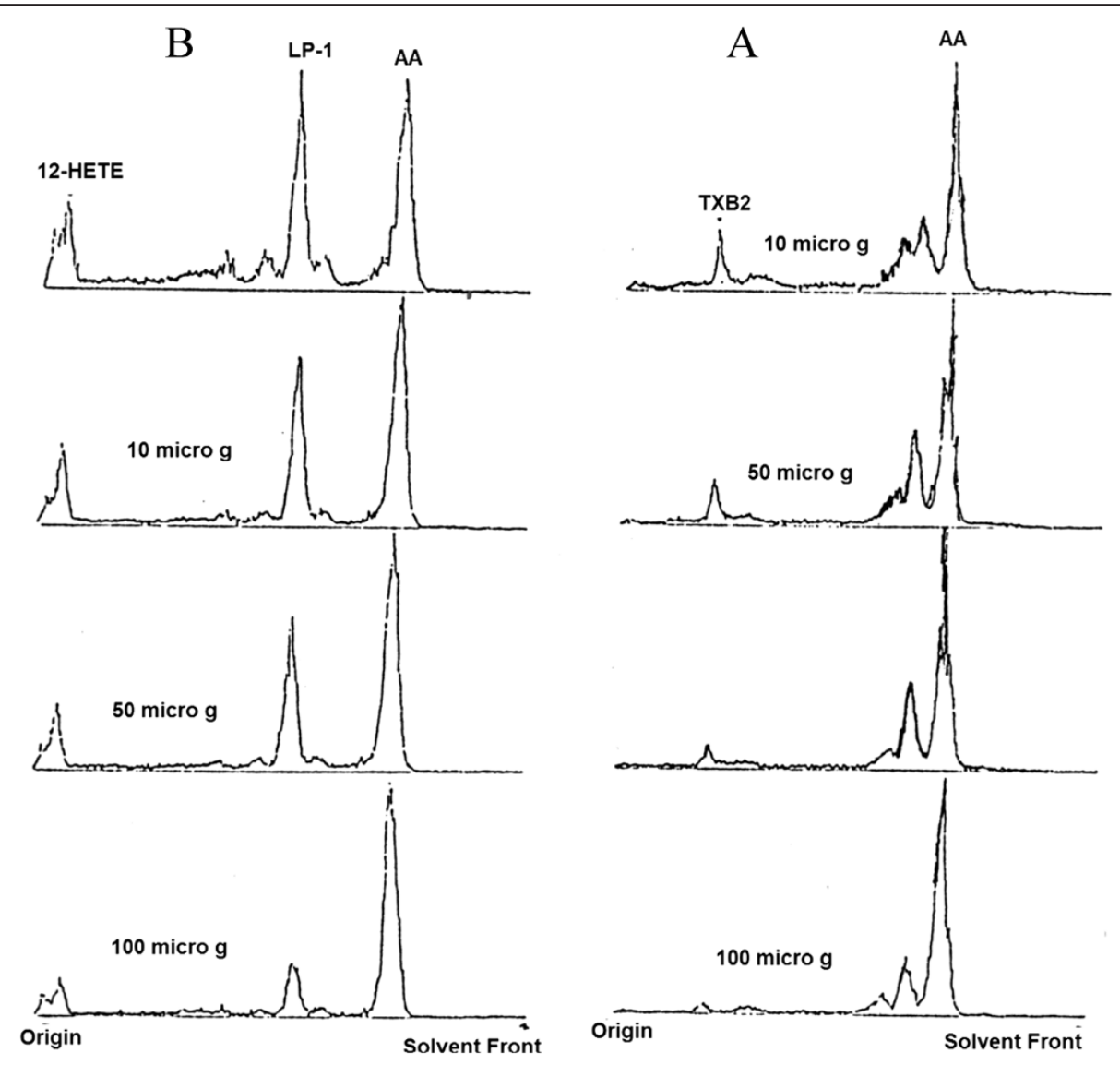

Figure 2 A representative scan of the effect of $n$-hexane fraction of HV on AA metabolism through COX (A) and LOX (B) enzymatic pathways. 


\section{Discussion}

Despite cardiovascular protective potential of available synthetic drugs, these drugs have various side-effects like skin rashes, bleeding, headaches and gastrointestinal problems. Therefore research is now directed towards green pharmaceuticals (medicines of plant origin) which are believed to be free from side-effects. Plants have been used for centuries to obtain treatment for various human diseases. One of the most important therapeutic targets for treating cardiovascular and inflammatory disease is the inhibition of AA metabolites through COX [28-30]. There are reports suggesting natural inhibition of AA metabolites [31]. Dual inhibition of LOX and COX pathways by natural compounds is also known and thought to be contributed by the secondary metabolism of plants $[32,33]$. Natural inhibitors of both inflammation and oxidative stress, however, are less common but could be of great therapeutic importance. Here in this report, we show that HV strengthens the antioxidant defense system and inhibits LOX and COX pathways of AA metabolism.

In the present investigation, crude extract of $\mathrm{HV}$ showed potent inhibition of AA-induced platelet aggregation, was partially effective against PAF and collagen while no significant effect was observed against ADP. These results suggest that crude fraction inhibits platelet aggregation mainly acting through COX pathway as AA induces platelet aggregation after conversion to TXA2 by platelet COX enzyme. Inhibition of thromboxanemediated platelet aggregation, however, seems to be a common mechanism shared by many other plants [3,15-17,34]. Further experiments with AA metabolism also suggest that crude fraction blocks COX mediated pathway of AA as it significantly inhibited TXB2 production from AA while both metabolites of LOX pathway were only partially inhibited. Crude extract was devoid of any significant effect on GPx, however, SOD activities were strongly elevated by the application of crude extract.

Both COX and LOX enzymatic pathways are implicated in oxidative stress and studies indicate that inhibition of COX [26] as well as LOX [35,36] reduces oxidative stress. Our results show that crude extract of $\mathrm{HV}$ as well as all three fractions elevated SOD activity while only n-hexane fraction enhances GPx activity. Previous studies also suggest that inhibition of COX lowers the oxidative stress [37]. Rise in SOD activity are likely to be a consequence of COX inhibition which can up regulates antioxidant enzymes such as SOD [38]. Similarly COX-2 and GPx are inversely related [39] and the effect of HV in this case may be related to its ability to inhibit COX. A number of studies show the presence of antioxidant potential of medicinal plants $[32,33]$ including increasing activities of SOD and GPx [26].
Aqueous fraction of $\mathrm{HV}$ did not show any significant activity against platelet aggregation with only partially inhibiting AA and collagen while having no significant effect on PAF and ADP. Interestingly aqueous fraction had no effect on LOX mediated metabolism of AA while only partial inhibition of $\mathrm{TXB}_{2}$ was observed suggesting aqueous fraction has less of compounds responsible for AA metabolism. This result also explains relatively low effect of aqueous fraction on AA-induced platelet aggregation. Just like crude extract, aqueous fraction showed strong elevation of SOD activity but ineffective against GPx. Consistent with previous studies [40,41], these results suggest that aqueous fraction has concentrated compounds that have potent effect on SOD and that the fractionation process has resulted in the distribution of compounds responsible for COX inhibition into other fractions as well.

Chloroform fraction of HV showed activities similar to the crude extract and akin to previous reports $[42,43]$, strongly inhibited $\mathrm{TXB}_{2}$ production and AA-induced platelet aggregation and having significant effect on elevating SOD activities. This suggests that chloroform fraction retains the activities contained in the crude extract and that fractionation process did not affect much in the distribution of phytocompounds in chloroform fraction. This also means that SOD elevation activity of $\mathrm{HV}$ is probably exhibited by more than one compound because aqueous fraction also had similar effects on SOD. Chloroform fraction of other plants has been shown previously to possess activities against platelet aggregation [44].

The pattern of activities observed with $n$-hexane fraction of HV was slightly different and exhibited strong effect against LOX-mediated metabolites of AA and significantly elevated GPx activity. These two activities are not shared by any other fraction, nor by the crude extract. Similar activities were previously found in n-hexane fraction of other plants $[45,46]$. This suggests that crude extract might contain ingredients that do not allow compounds responsible for these activities to show any significant effect and act as their blockers.

Metabolism of AA, especially by two enzymatic pathwaysLOX and COX produces various eicosanoids which play crucial role in inflammation [47]. Therefore, all the diseases with underlying inflammation are likely to benefit from inhibition of AA metabolism [48]. Since inflammation is associated with weakening antioxidant defense, the results of our study show that HV that possesses phytocompounds with anti-inflammatory as well as anti-oxidant potential can be used in such circumstances. Our study signifies the importance of $\mathrm{HV}$ as a starting point for the development of novel compounds against two of the most important enzymes implicated in inflammation in addition to enhancing activities of SOD and GPx. It is possible that separate compounds are responsible for activities related 
to COX, LOX, SOD and GPx; however, further, studies may also reveal that two or more of the above activities are possessed by a single phytocompound. Further characterization of HV and its fractions and isolation of pure compounds could provide us valuable information in this context.

\section{Conclusions}

Our study demonstrates that HV possesses activities against all human platelet agonists used in this study except ADP, and inhibited both COX and LOX pathways of AA metabolism. It also elevated the activities of SOD and GPx. However, these activities were distributed in various fractions. Therefore, it is unlikely that a single phytocompound is responsible for all these activities. Some fractions of HV showed more potent activities than others while certain fractions were almost completely devoid of antiinflammatory effect (aqueous). Interestingly, crude extract was unable to enhance GPx activity while n-hexane fraction which was obtained from the fractionation of crude extract, caused significant elevation of GPx activities.

\section{Competing interests}

The authors declare that they have no competing interests.

\section{Authors' contributions}

SG and SA conceptualized and performed the study, NK and QTZ analyzed the data, NBT and AH did literature search, HZEJ, MM and MZ did data analysis and manuscript writing. All authors read and approved the final manuscript.

\section{Acknowledgments}

Authors are thankful to Kohat University of Science \& Technology and University Brunei Darussalam for providing financial help to complete this work.

\section{Author details}

${ }^{1}$ PAPRSB Institute of Health Sciences, University Brunei Darussalam, Gadong BE1410 Bander Seri Begawan, Brunei Darussalam. ${ }^{2}$ Department of Pharmacy, Kohat University of Science \& Technology, Kohat 26000, Pakistan. ${ }^{3}$ Department of Surgery, Khyber Medical University Institute of Medical Sciences, Kohat 26000, Pakistan. ${ }^{4}$ Department of Medicine, Khyber Medical University Institute of Medical Sciences, Kohat 26000, Pakistan. ${ }^{5}$ Department of Biotechnology \& Informtics, Baluchistan University of Information Technology, Engineering \& Management Sciences, Quetta-87300 Quetta, Pakistan. ${ }^{6}$ Department of Crop Science, Faculty of Agriculture, University Putra Malaysia, 43400 Selangor, Malaysia. ${ }^{7}$ Department of Medical and Surgical Specialities, Transilvania University of Brasov, Brasov, Romania. ${ }^{8}$ The Patent Office, Karachi, Pakistan.

Received: 14 August 2014 Accepted: 28 October 2014 Published online: 26 November 2014

\section{References}

1. Wood R: The Whole Foods Encyclopedia. New York: Prentice-Hall Press; 1988

2. Behall KM, Scholfield DJ, Hallfrisch J: Diets containing barley significantly reduce lipids in mildly hypercholesterolemic men and women. Am J Clin Nutr 2004, 80:1185-1193.

3. Duh P, Yen G, Yen W, Chang L: Antioxidant effect of water extracts from barley prepared under different roasting temperatures. J Agric Food Chem 2001, 49:1455-1462.

4. Jeong JB, Hong SC, Jeong HJ: 3,4-Dihydroxybenzaldehyde purified from the barley seeds (Hordeum vulgare) inhibits oxidative DNA damage and apoptosis via its antioxidant activity. Phytomed 2009, 16:85-94.

5. Choi KC, Hwang JM, Bang SJ, Son YO, Kim BT, Kim DH, Lee SA, Chae M, Kim $H$, Lee JC: Methanol extract of the aerial parts of barley (Hordeum vulgare) suppresses lipopolysaccharide-induced inflammatory responses in vitro and in vivo. Pharm Biol 2013, 51:1066-1076.

6. Khare CP: Indian Medicinal Plants-An Illustrated Dictionary. Heidelberg: Springer Publishers; 2007

7. Shah JG, Patel BG, Patel SB, Patel RK: Antiurolithiatic and antioxidant activity of Hordeum vulgare seeds on ethylene glycol-induced urolithiasis in rats. Indian J Pharmacol 2012, 44:672-677.

8. Hokazono H, Omori T, Yamamoto T, Akaoka I, Ono K: Effects of a fermented barley extract on subjects with slightly high serum uric acid or mild hyperuricemia. Biosci Biotechnol Biochem 2010, 74:828-834.

9. Tsai CJ, Leitzmann MF, Willett WC, Giovannucci EL: Long-term intake of dietary fiber and decreased risk of cholecystectomy in women. Am J Gastroenterol 2004, 99:1364-1370.

10. Goldberg RJ, Ciampa J, Lessard D: Longterm survival after heart failure, a contemporary population-based perspective. Arch Intl Med 2007, 167:490-496.

11. Murtaugh MA, Jacobs DR, Jacob B: Epidemiological support for the protection of whole grains against diabetes. J Proc Nut Soc 2003, 62:143-149.

12. Etoh $H$, Murakami $K$, Yogoh $T$, Ishikawa H, Fukuyama $Y$, Tanaka $H$ : Anti-oxidative compounds in barley tea. Biosci Biotechnol Biochem 2004, 68:2616-2618.

13. Zia-UI-Haq M, Shahid SA, Ahmed S, Ahmad S, Qayum M, Khan IU: Anti-platelet activity of methanolic extract of Grewia asiatica L. leaves and Terminalla chebula Retz. fruits. J Med Plants Res 2012, 6:2029-2032.

14. Zia-ul-Haq M, Khan BA, Landa P, Kutil Z, Ahmed S, Qayum M, Ahmad S: Platelet aggregation and anti-inflammatory effects of garden pea, desi chickpea and kabuli chickpea. Acta Poloniae Pharma 2012, 69:707-711.

15. Zia-Ul-Haq M, Ahmed S, Rizwani GH, Qayum M, Ahmad S, Hanif M: Platelet aggregation inhibition activity of selected legumes of Pakistan. Pak J Pharm Sci 2012, 25:863-865.

16. Hussain J, Jamila N, Gilani SA, Abbas G, Ahmed S: Anti-Platelet aggregation, antiglycation, cytotoxic, phytotoxic and antimicrobial activities of extracts of Nepeta juncea. African J Biotech 2009, 8:935-940.

17. Hussain J, Khan FU, Gilani SA, Abbas G, Ahmed S, Khan AU, Choudhary MI: Antiglycation, antiplatelets aggregation, cytotoxic and phytotoxic activities of Nepeta suavis. Latin Amer J Pharm 2010, 29:573-578.

18. Imran I, Hussain L, Ahmed S, Rasool N, Rasool S, Abbas G, Ali MY: Antiplatelet activity of methanolic extract of Acacia leucophloea bark. J Med Plants Res 2012, 6:4185-4188.

19. Ahmed S, Gul S, Gul H, Bangash MH: Anti-inflammatory and anti-platelet activities of Avena sativa are mediated through the inhibition of cyclooxygenase and lipoxygenase enzymes. Int J Endorsing Health Sci 2013, 1:62-65.

20. Ahmed S, Gul S, Gul H, Bangash MH: Dual inhibitory activities of Adhatoda vasica against cyclooxygenase and lipoxygenase. Int J Endorsing Health Sci 2013, 1:14-17.

21. Aslam R, Saeed SA, Ahmed S, Connor JD: Plasma lipoproteins inhibit platelet aggregation and arachidonic acid metabolism in experimental hypercholesterolemia. Clin Exp Pharmacol Physiol 2008, 35:656-662.

22. Saeed SA, Connor JD, Quadri J, Tasneem S, Ahmed S, Mesaik MA, Choudhary MI: Inhibitors of phosphatidylinositide 3-kinase: effects on reactive oxygen species and platelet aggregation. Pharmacol Rep 2007, 59:238-243.

23. Saeed SA, Ahmad N, Ahmed S: Dual inhibition of cyclooxygenase and lipoxygenase by human haptoglobin: its polymorphism and relation to hemoglobin binding. Biochem Biophys Res Commun 2007 353:915-920.

24. Saeed SA, Motiwala A, Qureshi ZU, Khan R, Ali A, Quadri J, Ahmed S: Mechanisms of platelet aggregation mediated by G-protein coupled receptors in human platelets. J Coll Physicians Surg Pak 2006, 16:167.

25. Ahmed S, Gul S, Zia-UI-Haq M, Stanković MS: Pharmacological basis of the use of Acorus calamus L. in inflammatory diseases and underlying signal transduction pathways. Latin Amer Caribbean Bull Med Aromatic Plant 2014 13:38-46.

26. Gul S, Ahmed S, Gul H, Kaneez KF: Investigating the protective effect of Solanum melongena. Asian J Health 2011, 1:276-294.

27. Gul S, Ahmed S, Gul H, Shad KF, Zia-Ul-Haq M, Badiu D: The antioxidant potential of Brassica rapa L. on glutathione peroxidase, superoxide dismutase enzymes and total antioxidant status. Revista Română de Medicină de Laborator 2013, 21:161-169. 
28. Saeed SA, Khan SK, Ahmed S: The inhibition of prostaglandin biosynthesis by human plasma and its relationship to albumin and haptoglobin. J Bio Sci 2003, 3:1188-1202.

29. Saeed SA, Ahmed S, Ali A: A New Function of Human Haptoglobin: Endogenous inhibition of prostaglandin biosynthesis and its relation to hemoglobin binding. J Medical Sci 2003, 3:344-357.

30. Saeed SA, Rasheed H, Ali TH, Ahmed S: Mechanisms of inhibitory actions of cyclooxygenase-2 inhibitors in human platelets. J Bio Sci 2004, 4:515-520.

31. Saeed SA, Ahmed S: New aspects of cyclooxygenase-2 inhibition in myocardial infarction and ischaemia. Res Comm Molecul Pathol Pharmacol 2005, 117-118:167-178.

32. Saeed SA, Ahmed S: Anti-ischemic effects of nimesulide, a cyclooxygenase-2 inhibitor on the ischemic model of rabbit induced by isoproterenol. Arch Pharm Res 2006, 29:977-983.

33. Saeed SA, Ahmed S: Role of cyclooxygenase- 2 in myocardial infarction and ischemia. J Coll Physicians Surg Pak 2006, 16:324-328.

34. Bukhari IA, Khan RA, Gilani AH, Ahmed S, Saeed SA: Analgesic, anti-inflammatory and anti-platelet activities of the methanolic extract of Acacia modesta leaves. Inflammopharmacology 2010, 18:187-196.

35. Lee JA, Song HY, Ju SM, Lee SJ, Seo WY, Sin DH, Goh AR, Choi SY, Park J: Suppression of inducible nitric oxide synthase and cyclooxygenase-2 by cell-permeable superoxide dismutase in lipopolysaccharide-stimulated BV-2 microglial cells. Mol Cells 2010, 29:245-250

36. Chinnici CM, Yao Y, Ding T, Funk CD, Praticò D: Absence of 12/15 lipoxygenase reduces brain oxidative stress in apolipoprotein E-deficient mice. Am J Pathol 2005, 167:1371-1377.

37. Czapski GA, Czubowicz K, Strosznajder RP: Evaluation of the antioxidative properties of lipoxygenase inhibitors. Pharm Rep 2012, 64:1179-1188.

38. Kwiecien S, Konturek PC, Sliwowski Z, Mitis-Musiol M, Pawlik MW, Brzozowsk B, Jasnos K, Magierowski M, Konturek SJ, Brzozowski T: Interaction between selective cyclooxygenase inhibitors and capsaicin-sensitive afferent sensory nerves in pathogenesis of stress-induced gastric lesions. Role of oxidative stress. J Physiol Pharmacol 2012, 63:143-151.

39. Liao X, Wang L, Yang C, He J, Wang X, Guo R, Lan A, Dong X, Yang Z, Wang $\mathrm{H}$, Feng J, Ma H: Cyclooxygenase mediates cardioprotection of angiotensin-(1-7) against ischemia/reperfusion-induced injury through the inhibition of oxidative stress. Mol Med Rep 2011, 4:1145-1150.

40. Banning A, Kipp A, Schmitmeier S, Löwinger M, Florian S, Krehl S, Thalmann $S$, Thierbach $R$, Steinberg $P$, Brigelius-Flohé R: Glutathione peroxidase 2 inhibits cyclooxygenase-2-mediated migration and invasion of ht-29 adenocarcinoma cells but supports their growth as tumors in nude mice. Cancer Res 2008, 68:9746-9753.

41. Ahmed S, Gul S, Gul H, Zia-Ul-Haq M, Iram S, Jaafar HZ, Moga M: Scientific basis for the use of Cinnamonum tamala in cardiovascular and inflammatory diseases. Exp Clin Card 2014, 20:784-800.

42. Ahmed S, Gul S, Gul H, Shad KF, Zia-UI-Haq M, Ercisli S, Jaafar HZ, Moga M: Clinical justification of ethnomedicinal use of Brassica rapa in cardiovascular diseases. Exp Clin Card 2014, 20:764-783.

43. Zhao WX, Jin MH, Li T, Wang YJ, Quan JS: Intervention effect of aqueous fractions from Boschniakia rossica on hepatic oxidative stress in mice with liver injury induced by carbon tetrachloride. Zhongguo Zhong Yao Za Zhi 2013, 38:875-878.

44. Son DJ, Lim Y, Park YH, Chang SK, Yun YP, Hong JT, Takeoka GR, Lee KG, Lee SE, Kim MR, Kim JH, Park BS: Inhibitory effects of Tabebuia impetiginosa inner bark extract on platelet aggregation and vascular smooth muscle cell proliferation through suppressions of arachidonic acid liberation and ERK1/2 MAPK activation. J Ethnopharmacol 2006, 108:148-151.

45. Thiombiano AME, Adama $H$, Jean BM, Bayala B, Nabèrè $O$, Samson G: In vitro antioxidant, lipoxygenase and xanthine oxidase inhibitory activity of fractions and macerate from Pandiaka angustifolia (Vahl) Hepper. J Applied Pharm Sci 2014, 4:009-013.

46. Konaté K, Souza A, Coulibaly AY, Meda NT, Kiendrebeogo M, Lamien-Meda A, Millogo-Rasolodimby J, Lamidi M, Nacoulma OG: In vitro antioxidant, lipoxygenase and xanthine oxidase inhibitory activities of fractions from Cienfuegosia digitata Cav., Sida alba L. and Sida acuta Burn f. (Malvaceae). Pak J Biol Sci 2010, 13:1092-1098.
47. Ahmed S, Gul S, Zia-Ul-Haq M, Riaz M: Hypolipedemic effects of nimesulide and celecoxib in experimentally-induced hypercholesterolemia in rabbits. Turk J Med Sci. In Press.

48. Ahmed S, Gul S, Gul H, Zia-Ul-Haq M: Cyclooxygenase-2 inhibition improves anti-oxidative defence during experimental hypercholesterolemia. Bosn J Basic Med Sci 2014, 14:63-69.

doi:10.1186/s12967-014-0316-9

Cite this article as: Gul et al:: Multiple pathways are responsible for Anti-inflammatory and Cardiovascular activities of Hordeum vulgare L.. Journal of Translational Medicine 2014 12:316.

\section{Submit your next manuscript to BioMed Central and take full advantage of:}

- Convenient online submission

- Thorough peer review

- No space constraints or color figure charges

- Immediate publication on acceptance

- Inclusion in PubMed, CAS, Scopus and Google Scholar

- Research which is freely available for redistribution
C Biomed Central 